\title{
Towards an Ecological Understanding of Translation Eternality in the Context of Iran
}

\author{
Maryam Shirdel \\ Imam Reza International University, Mashhad, Iran
}

\author{
Majid Elahi Shirvan \\ University of Bojnord, Bojnord, Iran
}

\begin{abstract}
This study attempted to investigate the similarities and differences regarding the conceptions of translation eternality among a small group of Iranian people of different social positions and different ages. Sixty-two participants were selected based on the maximum variation sampling. To gather data, semi-structured interview was utilized. The participants were asked a list of 11 questions collected from the existing literature on the similar topics. Then, the interviews were transcribed for analyzing the data. Besides, Erikson's (1959) theory of development was used to classify participants of different ages in four groups of teenager, young, middle age, and old. The high frequency factors were found and analyzed with the use of Bronfenbrenner's (1979) nested ecological model. Moreover, the participants were classified in 11 groups based on their social positions and their conceptions were analyzed with the same method. Broadly speaking, 17 central tendencies in the interviews were obtained: People mainly focused on subjects of the books, translation fluency, author's competence in writing, and translator's competence, translations which have common grounds with social events of Iran, advertisement, existence of movie or cartoon adaptation of the book, translator's awareness of the content of the book, existence of cultural similarities between the source and target culture, popularity of the translator, author, and the original book, conversational language in translation, translation fidelity, being both translator and author, and effect of censorship on translation. Besides, old participants seemed to have more precise view on translation eternality and teenager's concerns were mostly about the appearance-related issues.
\end{abstract}

Keywords: translation eternality, ecological understanding, nested ecological model, translation competence, translation fidelity

\section{Introduction}

In the current society of Iran, there is a flood of translations produced by graduated students of translation studies or those proficient in the other languages. Therefore, in such situation, the reader can hardly find a well-translated book that would be able to absorb him/her. Besides, due to the economic problems, increase in the cost of paper, and slack market, printing industry faces a financial recession. Hence, publication of low quality translations worsens the situation for them.

Translation studies' turn toward culture along with the findings of the scholars of this discipline caused raising so many questions about social or cultural aspects of translation. For example, "why are all the translations of a single work not equally welcomed by the readers?", "why are some translations buried in the 
bookshelves of the bookstores forever?", and at the opposite side, "why do some translations not only lose their attraction for the readers, but also become the favorite of the next generations or even find more popularity than before?". Despite abundant studies done on the social aspects of translation with variety of methods and from different perspectives and attempts of so many researchers to identify the characteristics of a good translation, still the mystery of eternality of some translations has not been disclosed. Moreover, by far people's opinion was not involved in the selection of features of a good translation and it was done through theories of translation and strategies and techniques used while translating.

When talking about eternality of the translated literature, usually people ascribe it to the high quality translation. Although, in a field such as translation in which there is not an absolute and directly measurable criterion for identifying the quality, high quality translation is relative. Many translation researchers admit that social conditions have an outstanding impact on the process of translation and "the viability of a translation is established by its relationship to cultural and social conditions under which it is produced and read" (Venuti, 2008, p. 18). Hereupon, in the light of current problem, the need to focus on factors affecting translation eternality stands out. So, the aim of this study is to investigate and discover the main factors of translation eternality in the context of Iran, and the role of intermediary agents on the translation eternality. Besides, Bronfenbrenner's $(1979,1993)$ ecological model was utilized to explore to what extent an ecological perspective contributes to translation eternality and individual's conception of eternality of translated literature.

\section{Background}

In the past few years, European translation scholars have tried to investigate translation from a sociological perspective, and some of them such as Wolf and Fukari (2007) considered translation as a social action. Translation as an interdisciplinary branch which has roots in both Sociology and Linguistics benefits from numerous studies on sociological translation from different perspectives (see e.g., Bassnett \& Lefevere, 1998; Wolf \& Fukari, 2007; Venuti, 1996; Even-Zohar, 1978, 1990). However, these researches mostly explored the governing conditions of the production and reception of the literary works in the textual dimension. Therefore, they cannot examine the linkage between different activities related to the translation comprehensively (Bassenett \& Lefevere, 1998).

Social and cultural actions and thus theoretical and methodological conceptualization of them cannot be considered as independent elements, for they are closely related to each other. Accordingly, translation analysis will not be fully understood, if we only put the focus on the social aspect and forget about the conditions which form translation as a social act, related to the factors such as power, ideology, etc. Hereupon, using Chesterman's (2007) model, which studies translation from four different perspectives, is helpful to explore the reasons of translated literature's eternality:

(1) The linguistic level focuses on text, as linguistic data in written or oral form;

(2) On the cultural level, the focus is on ideas, on the transfer of cultural elements between different repertoires or polysystems;

(3) Research on cognitive dimension is interested in the decision making process, translator's mind processes, and the influence of different factors;

(4) Sociological research includes such topics as translation market and the role played by the publishing industry and other agents; 
(5) Chesterman (2007) believed the linguistic level looks at the relations between translations, their source texts, parallel non-translated texts in target language, and other translations. It is thus interested in concepts such as equivalence, naturalness, and fluency.

\section{Naturalness}

One of the main requirements in any translation, and certainly an eternal translation, is that the translation must sound natural. "Natural language is a language which is readable by everybody, however, it is formal" (Newmark, 1988). Yet, there exists no agreement on the term's definition. So many translation scholars proposed theories to provide translators with a way by which a natural translation be produced. In addition, different terminologies have been used to as equal substitution for natural translation. Herein, with the proposed definition of naturalness, the point to discover is to what extent naturalness of the translation is important for the reader in Iran context.

\section{Fidelity}

The idea of fidelity in translation has been under debate since the early translations of St. Jerome and Horace up to now. At first, the meaning of fidelity in scholar's mind was different from that of contemporary ones. Indeed, it was not until the end of the 17th century that fidelity had come to be generally identified with faithfulness to the meaning rather than the words of author. Kelly, Dryden, Tytler, Jonson, Dolet, and so many others have discussed the issue. Among them Dryden reduces all translations to three categories:

Metaphrase: "word by word, and line by line" translation, which (1) corresponds to literal translation; (2) paraphrase: "translation with latitude, where the author is kept in view by the translator, so as never to be lost, but his words are not so strictly followed as his sense"; and (3) imitation: "forsaking" both words and sense; this corresponds to what today might be understood as adaptation (Munday, 2009).

Here the quest is which category is more favorable to Iranians about eternal translations.

\section{Reader Oriented Translation}

The relation between translation and its acceptance by the reader is not a new topic in translation studies. In fact, this has been the question for a long time. Despite abundant studies done on reader oriented translation or writer oriented one, there is still no consensus on the matter which method is more effective to enhance translation quality. Both approaches have their advocates. Tytler, Dryden, Schleiermacher, and so many others worked on this subject and proposed so many labels such as domestication and foreignization, naturalizing and alienating, etc.; the researcher in this study tries to investigate which approach leads to eternality of a translated book.

As mentioned above Chesterman (2007) believed some issues such as cultural identity, cultural insight, and the relationship between central position and the position of marginal literary systems and power are explored at cultural level. So here are the possible issues at this level.

\section{Death of the Author}

Translation requires creativity and individuality of the translator. In the past, the position of the author and translator were totally separated, but today some theorists believe the authorship of the translator should be recognized. The discussion of translator creativity is associated with post modern theory that removes all the 
boundaries, recognizes the translator's individuality, and welcomes the new approaches (Perteghella \& Loffredo, 2006).

Lawrence Venuti may be of the most significant scholars who grant the right of authorship to the translator. He initially criticizes the romantics' view. According to romantics, creativity only belongs to the original author of the text and translating is just considered as a secondary or imitative job (Venuti, 1992). Venuti's criticism is greatly in line with the prevailing literary ideology. As Barthes and Foucault had been announced "death of the author" many years ago, Kristeva has been extracted intertextuality theories from Bakhtin's works, and the idea that creativity has essentially a translative nature has become a part of principals of postmodern. Now it should be investigated that current Iran society advocates which one.

A Canadian sociologist, Erving Goffman, presents a clear and controversial interpretation of authorship. He gives the author a principal role. That is, the one who expresses his own idea and who takes the responsibility for what he says (Goffman, 1981). He also poses another useful distinction between author and animator. By animator he means the one who tells the words but they are not of his own, but of someone else's. Example of this includes direct or indirect quotation, imitation, performing on stage, etc. In this study, it will be examined which role Iranians give to the author and translator.

\section{Cultural Effects of Translation}

Translation is not just an interlinguistic process. It consists of cultural nuances and cannot be created within cultural and political vacuum. Translator should voraciously look for new political or social thoughts, in order to bring changes to his own society. To cite an example, it is useful to refer to Etemadasslataneh (a politician in Naseri Period in Iran). At Naseri period translation center was established, and Etemadasslataneh was supervisor of many translations that took place from different languages to Persian. Studying in detail the books and articles which were translated according to his order, his choice, or by king's advise, one may reach a comprehensive understanding of these translation's influence on different levels of the society.

Another example is a book about medical vaccination given to Abbas Mirza by an English doctor; and an Iranian medicine man who knew English and translated that to Persian. It was an affective book in the history of public health in Iran. Similarly, many other translations do exist that had big impacts on cultural or political situations in different communities. This study is about to explore whether similar translations do exist in current society of Iran or not.

\section{Normal or Abnormal Process of Translation of a Work}

At the cognitive level, the process of doing a translation has apparent effects on the quality of translations. Since the translation market is competitive one, sometimes publishers try to release translation of a new book as quickly as possible and before their competitors to achieve the desired profit. For instance, a controversial book published a few years ago was The Secret Mulroney Tapes by Peter C. Newman. The publication process of this book was done secretly in "Random House Institute of Canada". "Fide" publication institute volunteered for publishing the translation of the book. And its authorities came to decision that publication of this book will make money for the institute under the condition of publicizing it within three months. So they employed three professional translators and divided the book into three parts, and allocated each part to a translator. This situation made the process of editing and coordinating of the translations a difficult job (Buzelin, 2007). Since 
usually the firsts are more eternal in mind, it should be investigated that creating such translations does lead to their eternality as well, or not.

\section{Translator's Competence}

Translation is in theory an interdisciplinary field and in practice a multitasking activity that requires much more than "merely" a linguistic competence in two languages. One of the widespread misconceptions concerning translation is that anyone with a decent knowledge of a foreign language not only can produce texts in his second language, but also can translate as well. Although knowledge of a foreign language is the basic prerequisite for translation, it does not guarantee that the resulting product will be adequate for its readership. Since translator's performance involves combination of quite a variable set of activities, its description as a single entity seems nearly impossible. Amparo Hurtado Albir (2002) perceives translation competence as "the ability of knowing how to translate". So this factor seems to be significant one at the cognitive level.

At the sociological level, the focus is on translation event which begins with ordering translation by customer, continues with passing different steps of translation process, and ends in being influenced by different actors involved in the process of translation. There exist many steps within the starting point of this process (customer's order) to the end of it (offering product to the audience); the agents involved in this process should deal with various human and non-human resources to carry out their duties.

For instance, Lefevere was the first one who has explored the impact of relations of power and ideology on the process of translation. In his 1992 research, he attempted to put the social monitoring factors (ideology and specific conditions governing literary system) and individual monitoring factors (powerful and influential individuals) in the spotlight of the experts and researchers of translation studies domain. Lefevere believed that the task of this element is to control the particulars of the translation process and its prevailing social and cultural conditions.

In Iran, after forcing Reza Shah to abdicate the throne in September 1941 and Allied occupation of Iran, the repressive state of police and censorship collapsed. Following this change, lock was removed from pen of expression and many intellectual endeavours in various areas began to appear. Among them three highlighted discourses were Nationalism, Leftism, and Islamism. The three discourses and their impacts can be seen from 1941 to 1953, which is until the coup of August 15, in authorship, translation, journalism, political and trade organizations, and even in milder movements which are called "Civil Society Movements" nowadays. So in this study, the role of power and governing conditions on translations need to be explored.

\section{Ecology}

An ecological perspective is an analysis and study of interactions among organisms and their environment, also described as a standpoint for conceptualizing the changing maturing person in relation to a changing environmental-social, physical, and psychological aspects. The aim of ecological perspective is to study individuals as social beings relating to their immediate environments (Tudge, 1997).

\section{Vygotsky's Cultural Historical Theory}

Vygotsky's (1994) cultural-historical theory clearly linked development with social context. In his theory, learning takes place through interaction with different components, and all development is framed within a context that is socially created at both local and broad societal levels and is affected by the developing nature of the individual. In fact, he proposed that human development should span four different but interrelated domains: 
(1) The phylogenetic level which concerns the development of humankind as a natural species;

(2) The cultural-historical level which focuses on development in terms of the broader external world within which humans exist;

(3) The ontogenesis which shifts the focus to the development of the individual subject across the human life span;

(4) The microgenetic development, the momentary instance of concrete practical activity that subjects engage in with the world around them.

\section{Bronfenbrenner's Nested Ecosystem Model}

Considering that human being never stops developing, Bronfenbrenner (1979) believed that a person's development is affected by different contexts (social, political, cultural, and historical) in his surrounding environment and focuses on the important relationship the child has with other people, policies, and systems in his immediate and wider environment. He offers a conceptualisation of the child's environment (ecology) as a multi-layered set of nested and interconnected environmental systems. He divided the person's environment into five different levels: the microsystem, the mesosystem, the exosystem, the macrosystem, and the chronosystem. While this study deals with the first four categories.

(1) Microsystem: The first level of Bronfenbrenner's theory is the microsystem. The microsystem is the system closest to the person and the one in which he has direct contact. For example, at the closest level to the child, socialisation within the microsystem is influenced by those who are emotionally and practically closest to the individual (e.g., parents, carers, and family). Much of the contact at this level is face-to-face, but often limited to dyadic relations. If we consider translation as the central core of the system, the subject of the book will be a factor of the microsystem.

(2) Mesosystem: The next level of ecological systems theory is the mesosystem, consisting of the interactions between the different parts of a person's microsystem. Characterised by the relations between multiple microsystems, the mesosystem is about "connections between contexts" (e.g., the inter-relationships between the home, day care centre, and schools). The mesosystem is where a person's individual microsystems do not function independently, but are interconnected and assert influence upon one another. These interactions have an indirect impact on the individual. In a system, with translation as a subject, the relations of the original text and translation will constitute the mesosystem.

(3) Exosystem: The exosystem is the next level which refers to a setting that does not involve the person as an active participant, but still affects him. This includes decisions that exert influence upon the child, but in which he has no participation in the decision-making process (e.g., parents' place of work, governmental agencies). In a translation-centre system, advertisement will be a component including in exosystem, which has an indirect affect on the translation.

(4) Macrosystem: The fourth level of ecological system theory is the macrosystem. The macrosystem encompasses the cultural environment in which the person lives and all other systems that affect him. The macro-level is viewed as providing the broad cultural, ideological, and organizational patterns within which the meso- and exo-systems reflect the ecology of human development. While at first seeming far removed from the immediate ecology of the child's development, the macro-level is not static and may change through, for example, revolution, economic recession, war, or technological change. In the supposed system of translation based, publishing policies are placed at the macrosystemic level. 


\section{Method}

The participants of this study were comprised of 62 people, 34 males and 28 females, enrolled in the program from different class of society from Mashhad, Isfahan, and Shahin Shahr. Out of 62 persons, 42 of them were interviewed in Mashhad, 15 persons in Isfahan, and 5 of them in Shahin Shahr. The participants' age ranged from 15 to 70 . They were from different social positions such as university students, students, librarians, booksellers, publishers, teachers, university professors, engineers, housewives, translators, poets, employees, etc. The participants of this study were selected according to maximum variation sampling, since based on Dorneyi's (2007), this process allows the researcher to explore the variation within the respondents and it also underscores any commonalities that is found. All the participants' mother tongue was Persian and the interviews were done on Persian. Moreover, the participants were assured that their information would be confidential and their names were not asked and only some demographic information such as age, gender, level of education, and their job were asked.

In this field study, the data were gathered via interview. The rationale for choosing interview as the instrument for data collection was the fact that through interviews the researcher can gain an in-depth understanding of each participant's beliefs. This kind of interview also seems to be useful for this study since the aim is discovery rather than confirmation. So the participants were asked to answer the interview questions. As for the interview questions, the researcher studied as many articles as she could in the field and came up with a collection of probable interview questions. The list then was given to the supervisor of the study for the final revision and approval. The confirmed list of questions consisted of 11 questions on translation eternality.

The researcher utilized semi-structured interview to capture what people thought about translation eternality. After selecting participants, the actual data collection procedure started. Data collection was done since December 2014 to April 2015. As it has been suggested in Dorneyi (2007), the interview questions were sent to each participant just a couple of days before the interview day so that they could think about the questions if they felt it necessary. The interviewees were asked if they felt comfortable to record their voice. After their approval, the interviews were recorded by an MP3 recorder. And if they did not agree, the interviews were transcribed. At last, the recorded interviews were transcribed too, to be prepared for data analysis.

The participants' ideas were written separately. Then the frequent factors mentioned by them were recognized and collected to see what common factors do people share about translation eternality. Next, the participants were classified into two groups. First was based on their social positions, and second based on their age. The participants were placed in 10 groups based on their social positions as booksellers, employees, engineers, housewives, jobs related to the book, researchers, students, teachers, university students, and university professors. The frequent factors among each group were recognized and analyzed, too.

And at last, the participants were categorized by their age in four subcategories according to Erikson's classification. They were grouped as teenagers, young, middle-ages, and olds. The frequent factors in each subcategory were recognized, compared, and analyzed.

\section{Result and Discussion}

Before discussing the results in detail, the main factors mentioned by the interviewees and their frequency are presented in the Table 1. 
Table 1

Major Factors of Translation Eternality Drawn from Interviews

\begin{tabular}{ll}
\hline Factor & Number \\
\hline Subject of the book & 34 \\
Translation fluency & 19 \\
Author's competence & 18 \\
Translator's competence & 17 \\
Others' suggestion & 16 \\
Having common grounds with social events of Iran & 11 \\
Advertisement (media, TV, radio) & 11 \\
Existence of movie or cartoon adaptation of the book & 10 \\
Translator's awareness about the subject of the book & 10 \\
To use conversational language & 7 \\
Author's and translator's popularity & 7 \\
Cultural similarities between target and source culture & 6 \\
Being didactic & 6 \\
Translator's fidelity to the source text & 6 \\
To have universal subject & 6 \\
Being both translator and author & 6 \\
Plot of the story & 6 \\
Writing style & 4 \\
Addressing common issues of human being & 4 \\
Name of the book & 4 \\
Electronic file availability & 4 \\
Translator's knowledge of the target language & 4 \\
\hline
\end{tabular}

In the following part, the main factors obtained from the interviews are presented, compared, and discussed.

\section{Subject of the Book}

To summarize the findings, not surprisingly, the most frequent item mentioned by the participants was subject of the book, noted by them under different titles. A university student, who was an interpreter as well, claimed:

Any valuable story or poem which pictures moments of reflection of human beings about life and the universe is a discovery which widens the range of human spirituality and history; And in any language it has been written it is worthy of being translated to all existing languages for all the people to have access to that. Hence, this is the common point of all good literatures that makes them worth to be translated.

Among interviewees some believed that eternal books are those which address common issues of human beings. On the other hand, the others believed that an eternal book should be about neglected subjects in Iran. Six persons referred to universal subjects as a criterion that differentiates between eternal books and others. When they were asked what they meant by universal subjects or common issues of human beings, most of them agreed that there were common concepts all around the world that people, apart from their nationality and language, share; some concepts such as love, fear, death, peace, war, humanity, holiness, God, etc., are of those shared subjects among all human beings, about which is written everyday and everywhere.

The low frequency of subjects and high frequency of works are undeniable. That is, everyday different 
literary works are created around the world with similar subjects. For instance, a director of public relations of a cultural center said:

"Love" is a unique subject, but what makes some literary works such as Romeo and Juliet, Leili and Majnoon, or Spring Snow as masterpieces is the specificity of the technique used in writing these works. Thus, a common characteristic of eternal books is their innovation in subject or form; that is, they are not imitated. They are authentic. Herein, the Author has tried to reflect his own view and personality in his work to make it significant, while others may make commercial works.

\section{Translation Fluency}

The other factor which was frequent among participants was "translation fluency". By fluency, they meant reading without any peculiarities in the text that interrupt the process of reading and comprehension. Venuti's findings in regard to the invisibility of the translator and the dominance of the style of invisible and fluent translation in the English culture also support the result of the present study. He states:

A translated text, whether prose or poetry, fiction or nonfiction, is judged acceptable by most publishers, reviewers and readers when it reads fluently, when the absence of any linguistic or stylistic peculiarities makes it seem transparent, giving the appearance that it reflects the foreign writer's personality or intention or the essential meaning of the foreign text- the appearance, in other words, that the translation is not in fact a translation, but the "original". (Venuti, 2008, p. 14)

The language should be natural. This was stated by one of the participants who was chief editor of a magazine. He seemed to be in support of Newmark's (1988) definition of natural language (mentioned in background) and claimed:

Although the translator is allowed to be innovative and not to translate all the texts with a single tone and style, adherence to the framework defined in Persian is certainly necessary. A good literary translation is the one that can make use of the resources of the Persian in the best way and escapes cliché frameworks. To me the natural language of translation is the most important issue. I rather prefer to leave a book that pauses me regularly while reading. The translator should not go extremities. If necessary, some units in the context should be converted to the familiar Persian units to make the text more tangible and easier to be understood.

Therefore, so many translations of a single work may exist, yet that one which does not stop the reader and narrates the issue fluently is thought to be successful. And assuredly this refers to the translator's competence.

\section{Competence}

The next frequent factor that interviewees attribute to the translation eternality was competence of author and translator, which will be discussed separately.

\section{Author's Competence}

A participant in this study who was a bookseller seemed to have a comprehensive view of the authors. He believed that authors are people with special characteristics. He described them as emotional characters that react earlier than any other to the events around them. In fact, their different reactions to the events may explain why they are likely to vary from others. He mentioned that they have artistic worldview and the reflection of their worldview is evident in their works. In addition, the authors are knowledgeable. Therefore, the one who knows about the world and is able to analyze the things is the one who is able to create eternal works. If an author had such characteristics, he would be capable of watching carefully every single event, analyzing things with exact details, and then by adapting those to his worldview tries to create a masterpiece. Despite this 
sensitivity and artistic spirit, authors are the strongest and the most motivated people in the society, since in the worst conditions they create eternal works. A music master used a good simile to shed light on the issue:

A good writing can be likened to a piece of music that is harmonious and pleasant for its listener. Obviously, creation of such works could not be undertaken by a novice, but a creative and qualified musician is needed to be capable of composing that. So is writing. So many factors must be combined to see a beautiful text is emerged.

Another interesting issue mentioned by a teacher was the environment in which the work has been created. She expresses:

The level of civilization, progress and knowledge, the level of social conflict, social complexities, history and culture are somehow influential for the creator of the literary work and as a result for the work.

\section{Translator's Competence}

The other part is translator's competence. Most of the interviewees described competence as a series of elements and abilities that translator should possess in order to be a proficient one, which seems to be a paraphrase of Hurtado's (2002) definition (mentioned in the background). For instance, they referred to choosing proper equivalence that helps the reader not to be confused and leads to fluency of the text. Making cohesive translation, choosing free rather than word for word translation, and using simple language or (in their words) conversational language are the other elements focused by the participants.

Some interviewees see the essence of motivation and knowledge to make a proficient translator. They asserted that before starting translation, one should assure that he is knowledgeable and experienced enough to cope with probable difficulties happening while translating. One of participants of this study who was an interpreter and a university student as well said:

Some of my colleagues major in translation, but I do not think that a degree in translation actually means someone is qualified to be a full- time translator.

Or as a university professor in this study expresses:

Reading famous translators' biography or interviews, we will reach the point that the interest for reading or translating has been internalized in them since their childhood, while most of the current translators admit in translation or foreign languages majors in university accidently or by interest, and after graduation they try to translate to achieve fame or earn money; and this cases the creation of low quality translations.

The study also indicates that people preferred reading translations in which generally all the terms and phrases sound familiar to them. In other words, they advocate reader oriented translations. Participants believed translator who is familiar with both languages and cultures, should have the ability and creativity to create a translation from which target audience enjoys the same as source audience, and their understanding of the text is alike. Besides, it can be concluded that they were interested in translations in which the translator has reached to the state that, in a radical sense, the author is absent from the text, or as asserted by Barthes "Death of the Author" (Farquhar \& Fitzsimons, 2011) has occurred. Ahmad Shamloo was an example for creating such translations. His translation of The Little Prince by Exupery is one of the most popular masterpieces, which follows a poetic language to attract its own audience, children. For him, children were serious and important audiences; that if they like a translator in childhood, they will follow his translations in adulthood, too. 


\section{To Have Common Ground With Social Events of Iran}

The next major factor abstracted from the participant's talks was to have common grounds with social events of Iran. It can be claimed that art and literature are rooted in a particular period and a particular society; however, it is possible that another community in a certain circumstances rediscover and enjoy them. Thus, this is where translator's tact comes to his help to translate a book in accordance with people's need. Obviously, every historical period has its own books, related to its social events. For instance, at the time of the constitutional revolution in Iran, it was not possible to write about social realities, yet the desire for the independence of the country was shown by writing historical novels. The same happened for translations. Translators choose books to be translated according to the needs of the society and this leads to their popularity.

One of the booksellers who was graduated from political sciences states:

During Iran-Iraq war because of the lack of electricity and facilities, instead of talking about war and daily events of that time some families preferred reading books at soirees to pass the time. So many people in Iran started reading Zabihollah Mansoori's translations, which were full of descriptions and explanations to distance themselves from the war atmosphere and forget it just for a few hours. Since his translations were mostly historical novels, they motivated people to endure the difficulties and brought joy to them. I remember in one of his books a maid became the rebel leader like Spartacus to rescue the land and defeat the tyrant. Such stories were the exact need of the people at that time, and Mansoori understood that and wisely took advantage of that.

\section{Others' Suggestion}

Since per capita of reading in Iran is very low, and according to participants of this study, others' suggestion is a factor that motivates people to read books. Most of the students and university students stated that the books which they have read were introduced to them by others, mostly their teachers. So, teachers and university professors play a significant role in motivating their students for reading. Likewise, booksellers claim that their regular customers usually buy books which they offer to them, and whereas these people are knowledgeable enough about the subject, their suggestion are usually books worth reading.

\section{Advertisement}

One of the librarian believed that Iranians used to communicate with a subject, first in visual aspect, and afterwards they show willingness to it. Hence, the role of advertisement here stands out. To elaborate on the issue, maybe it is useful to quote a memory of Leili Golestan, one of the privileged Iranian translators, from her interview in Motarjem journal (2006). She talks about the translation of "Nothing, and So Be It" which was one of her early translations:

Amir Kabir press had printed large posters for "Nothing, and So Be It". All the streets ending to Tehran University were covered by them. They had advertised in newspapers too. Then Nixon came to Iran and the posters were removed! Nixon went and the posters were stuck again. And I understood that I should be more careful, both about choosing the book and about method I use for translating the text.

Thus, obviously if the works of novice and good translators were advertised, they would be motivated to choose the best books and best translating style for their next works, as a result they will be better translators.

Most of the interviewees focused on the role of advertisement on the popularity and consequently on the eternality of the book, however, all of them without exception agreed that advertisements in Iran whether about cinema or books are biased. They claimed some special books with unique subjects such as Da written by 
Seyyede Zahra Hoseini have the chance of being introduced in media or newspapers or even television. Although these books have their own audiences, they do not match with public tastes. A teacher states:

Even in the reading competitions in TV, radio or at school just religious or political books are the issue of the competition. Government and those who are responsible in this field should be aware that if the public taste of reading be taken into account certainly the per capita of reading will enhance.

Another weak point experienced by the researcher is allocating inappropriate time to the book review programs. For instance, the program "café radio" that criticizes, reviews, and introduces books is aired at midnight, thus just a particular group of people can be its audience. By the way, it can be said that advertising in Iran has been effective for a specific kind of books and does not include public taste.

\section{Existence of Movie or Cartoon Adaptation of the Book}

Some participants believed that another factor that may lead to eternality of a translation may be existence of movie or cartoon adaptation of the book. Some claimed they were encouraged to read a book after watching its movie adaptation or cartoon adaptation. This factor has more commonality among teenagers, some movies like Les Miserables, Alice's Adventures in Wonderland, The Little Match Girl, Daddy Long Legs, and The Little Princess are of those popular stories among them. Although these books are the old ones, showing their movie or cartoon adaptations can make them favorite stories of the next generation.

\section{Translator's Awareness of the Subject of the Book}

According to the participants of this study, translator's awareness of the subject of the book is a critical factor that leads to creation of acceptable translations. To create such a translation, just knowing the language is not enough. So this is evident that the translator should be familiar with the vocabularies associated with the text or jargons. For example, if the text is in the field of philosophy, it requires a translator with knowledge about the field; otherwise, the outcome will be vague, nonstandard, and full of errors. According to a bookseller:

Abdolhamid Nayer Noori had been translated "Thus Spoke Zarathustra" but it was not welcomed among readers. A few years later, Daryoosh Ashoori started translating this book, but since he thought he might not be familiar enough with the philosophy of Nietzsche, he asked Ismail Khoee, who had PHD in philosophy, to help him. The beauty of Ashoori's prose and Khoee's knowledge of the text has made the book everlasting, and in my idea that is why people usually know Thus Spoke Zarathustra with the translation of Daryoosh Ashoori.

\section{Cultural Similarities Between Source and Target Language}

Cultural similarities between source and target language are the next factor mentioned by some of the participants. When cultures are relatively similar, but languages quite differ, the translator is expected to use a lot of changes in forms. But if the cultures differ too much, translator's job will be much harder, since cultural difference create more complex problems than language differences. Briefly, the more cultural similarities between languages, the easier the act of translation. As Soroush Habibi (2002), who is currently one of the most professional translators in Iran, in an interview about the public interests of Iranians towards Russian literature says:

Iranians are interested in Russian literature, since Russians are emotionally very close to Iranians. Russians have rhythmic idioms and proverbs, poetic speeches, just like Iranians. Both countries were defeated by Moguls; many Russian words entered Persian and many Persian words transferred to Russian language. This all makes us feel closer and show interest to their literature. 


\section{Popularity of the Author and the Translator}

Popularity of the author is a leading cause of success of a book. It should be remembered that a person who gives birth to a book is the one who has critical role in its success and eternality. One of the publishers states that:

If the author is known, and several editions of his books have been published, it would be reasonable to expect that his new book would face a welcoming audience.

Even the translators usually prefer to choose books written by popular authors to translate. Moreover, interviewees claimed books they have read and the bad translations they envisaged and experienced that stopped them from reading, made them buy books written by known authors and translators rather than trying some new ones. Accordingly, some of the participants said it happened to them when they were in a dilemma for choosing books to buy and read they always preferred the one with the popular translator rather than the one with popular author. Since even if the original author creates a masterpiece, a bad translator can ruin all his efforts, although, the vice versa is possible, too.

\section{To Use Conversational Language}

The feedback from participants displays a general consensus that as it was mentioned before using conversational language is an encouraging factor for reading. Using simple language minimizes the distance between spoken and written language. A teacher participated in this study believes that Iranians life style has changed, and taste of reading has also followed this procedure. She said:

Poetry, literature, and criticism are not thought in an acceptable way to the students. And if someone follows literary works it is because of his family's condition. In the past book was people's entertainment, while it is replaced by cinema, television, and Internet. The time is shorter and the life speeds faster. A few are able to tolerate reading an eight hundred-page novel. In the past entertainments were not so much and parents were more acquainted with literature.

Besides, since nowadays everybody uses this simple language to send SMS or E-mails, this broken language seems more preferable. Accordingly, a bookseller said:

Today, the forms of entertainments are different from past. People prefer watching TV series and spending time on surfing the internet and do not want to hear hard, rhythmic words. That is why you want to read simple and fluent texts, do not like to spend time thinking about every single sentence, and swallow them like a piece of cake. That is why the translation of the little prince, by Ahmad Shamloo has been one of the most popular books in recent decades. He says that even on the cover of some of the books this phrase can be seen "written in simple language", and certainly if people have the right to choose their choice would be them.

\section{Translator's Fidelity to the Source Text}

Participants proposed a focus on the translator's fidelity to the source text; however, when talking about translator's fidelity to the source text, they were ambivalent. One of the booksellers who was a translator as well, believes that translator's fidelity to the source text is one of the main rules and necessities of a good translation he refers to the statement of Ezzatollah Fuladvand who was his friend:

The translation must be as faithful as it is possible to the original text. The translator should avoid writing vague and ambiguous sentences and he should bring what the author really had in mind on paper in a way that it matches the spirit of Persian. 
On the other side, most of the participants referred to Zabihollah Mansoori's works as eternal books. His translations are mostly historical novels. It can be said that he solved a few drops of original stories ink in a basin of his creativity, filled his pen with, and then he started writing translation. There are so many narrations about his works. Some say that he translates a sixty-page book to a six hundred-page one. Others claim that the authors of some of his translations even do not exist and he is the author himself, yet since Iranian mostly welcome the foreign author's works rather than domestic's, he prefers to publish them under the title of translation. Anyway, due to its fluency and attractive subjects, his translations are still worth to be read again and again.

Except aforementioned factors, some others do exist that were not frequent in interviewees' answers but seem to be of great importance. They are: translating in a single field, being both author and translator, Braille or audio version availability, and not being censored that indicates the role of power on translation. Moreover, it has many side effects for other parts of the society. A publisher in this study shed light on the issue:

Publication economy in recent years has been more damaged than ever before. Partly due to the economic situation of people, and partly due to the general downturn of the book market. This weak economy has had an impact on all those involved in the field. Publisher who takes lees profit of this work; not only lowers the number of books, but also tries to save money in all expenses as much as possible. As a result, many specialists are gradually removed from the cycle of book production. For example, they do not give the editors the translated books. The result is incorrect and low quality books that we see in bookstores.

\section{Age Category}

In the following part, in order to categorize people of different ages, development theory of Erikson's classification was used. Just one participant of the current study had more than 65 years, so he was placed in the old participants' category.

\section{Table 2}

Major Factors of Translation Eternality Drawn from Old Participants' Interviews

\begin{tabular}{ll}
\hline Old participants (50 years old and more) $\mathrm{N}=9$ & Number \\
\hline Factor & 5 \\
\hline Translation fluency & 4 \\
Subject of the book & 2 \\
Author's competence in writing & 2 \\
Cultural similarities between source and target culture & 2 \\
To have common grounds with social events of Iran & 2 \\
Translator's awareness of the content of the book & 2 \\
Translator's knowledge of the target language & 2 \\
Translator's competence & 2 \\
\hline
\end{tabular}

Translator's competence

Table 3

Major Factors of Translation Eternality Drawn from Middle Aged Participants' Interviews

\begin{tabular}{ll}
\hline Middle-aged participants (30-50 years old) $\mathrm{N}=22$ & Number \\
\hline Factor & 12 \\
\hline Translation fluency & 11 \\
Subject of the book & 5 \\
Translator's awareness of the content of the book & 5 \\
Translator's competence & 4 \\
Author's competence in writing & 4 \\
\hline
\end{tabular}


Table 4

Major Factors of Translation Eternality Drawn from Young Participants' Interviews

\begin{tabular}{ll}
\hline Young participants (20-30 years old) $\mathrm{N}=24$ & \\
\hline Factor & Number \\
\hline Subject of the book & 15 \\
Author's competence in writing & 10 \\
Translator's competence & 9 \\
Translation fluency & 8 \\
Others' suggestion & 7 \\
To have common grounds with social events of Iran & 5 \\
Cultural similarities between source and target culture & 5 \\
\hline
\end{tabular}

Table 5

Major Factors of Translation Eternality Drawn from Teenager Participants' Interviews

\begin{tabular}{ll}
\hline Teenager participants (12-20 years old) $\mathrm{N}=7$ & Number \\
\hline Factor & 5 \\
\hline Others' suggestion & 4 \\
Electronic file availability & 4 \\
Existence of movie or cartoon adaptation of the book & 4 \\
Name of the book & 4 \\
Subject of the book & 4 \\
\hline
\end{tabular}

As it can be seen in the tables, subject of the book had been one sure factor for all the ages to select a book as an eternal one.

Translation fluency was also a common point between what people of different ages believed regarding indicator of eternality. Yet, it seems that old and middle-aged people valued fluency as one of the basic principles of a good translation. Since $55.5 \%$ and $50 \%$ of them respectively referred to fluency, while $33.3 \%$ of young participants mentioned that and it was not suggested by the teenagers at all. It could be because the teenagers do not pay attention to this issue, or because they take it for granted and considered fluency as a must in translation.

Competence of the author and the translator was the other major factor abstracted from participant's talks and shared among most of them except teenagers. As it will be discussed in the part related to the results based on the social positions, teenagers' reading source is mostly limited to the books downloaded from the reading websites, in these websites, anonymous authors (if one can call them author) who are interested in writing whom usually do not have the experience of publicizing a book, start writing books (mostly novels), and then upload them in these websites without receiving any funding. Majority of their novels are romantic books written in a simple language, which are teenagers' favorite and form their taste of reading. Therefore, it is obvious why teenagers do not value author's or translator's competence. In order to enable them to recognize and correctly understand good texts, they should be provided with valuable classic books.

It seems that old participants care more about details of translations than others. One probable possibility is that it may be due to their social development, or as Vygotsky (1978) calls it their ontogenetic development, or it may be because of the social or political of that period that made them to be more careful about the details of event, and literary works as well; or in Vygotsky's words it raised from their social historical development. 


\section{Bronfenbrenner's Ecosystem Model}

To analyze the findings with reference to Bronfenbrenner's (1993) four ecosystems, they should be debated from two different points of view:

(1) To consider the translation competence as the core of the system;

(2) To consider the individual as the core of the system.

\section{Translation Competence as the Core}

If translation competence is considered as the center of the system, at the microsystemic level 11 factors will be unfolding about translation eternality which is identified as influencing translation. The data also suggested the existence of meso-, exo-, and macrosystem that exerted influence on the translation eternality.

At the microsystemic level. The factors at the microsystemic level are reported in two strands: (1) those factors which are directly under the influence of the translator and his skill and (2) the factors dependent on both translator's skill and original text.

Translator's competence dependent factors. The data indicates that people shared the belief that fluency of the translation paves the way for making an eternal translation and as it was discussed before, a fluent translation cannot take place without translator's tact. Despite participant's initial favorable attitude toward pseudo-translations of Zabihollah Mansoori, they claimed that they advocate faithful translations.

Translator's competence is another factor at the microsystemic level affecting translation. Choosing proper equivalents, using appropriate tone, and coping with the complexities occurring during the process of translation do not happen without an experienced translator who has been grown up in an environment filled with reading and translating. As a university professor noted:

Reading translator's biography or their interviews, you find out that the interest for book and its reading have been internalized in their characters.

This is not just a claim. Mohammad Ghazi (1993), one of the best translators in Iran's history in an interview with Motarjem journal focused on the translator's knowledge of the target language and said: "At the age of thirty four I memorized more than fifty thousand lines poems of Iranian poets".

This was also confirmed in this study. When questioned on their beliefs about language of an eternal translation, most participants held that the translator should have profound knowledge of target language, in order to create an acceptable translation.

Besides, being both translator and author is another translator's dependent factor identified to enhance translation quality. A translator who has the experience of authorship not only owns better writing competence, but also can more easily deal with the complexities happening during the process of translating the text.

According to the interviewees, translator's awareness about the content of the book is a factor that prevents vague translations created due to the translator's ignorance. Therefore, a competent translator initially reads about the topic and then starts the process of translation with enough background knowledge.

And the last factor identified in this excerpt is translation popularity that enhances chance of the fame of the book.

Factors both dependent on the translator's competence and original book. Compared to the aforementioned factors, the upcoming ones appeared to be linked to the source text, too. Translator is the one who chooses which book to translate according to the community's need and his interest, thus subject and more specifically, universal subject of the book is that dependent to the translator's good choice. 
Plot of the story is accounted as another typical affective factor at the microsystemic level, related to how translator transfers what exists in the source text. Whether translator's fidelity to the original text's interesting plot, or his creativity in changing a linear and boring story into a dramatic one which is full of ups and downs, the great impact of the translator is undeniable.

As participants claimed name of the book could be an encouraging factor in reading choice. Although the name of the book is inherited from the original one, compatible and suitable translation of the name is accounted as definitive to the translation and its success.

All the factors reported here are related to the translator's experience and development of him across his life span or as Vygotsky (1978) suggests ontogenetic development of the translator. These are known as primary but significant factors without which translation does not qualify to be granted the title of eternal one.

At the mesosystemic level. The linkage between translation and original author and text were perceived to constitute the mesosystem. This could be found in the fact that author's competence in writing, his writing style, and his popularity exerted a significant effect on the translator's choice of the book at the microsystem. Certainly, the translators prefer to translate the work of the famous author whose competence in writing has been approved before, rather than the one whose inexpert writing stops him frequently.

The participants also believed that books addressing common issues of human being are the ones whose chance of being eternalized is more than others.

At the exosystemic level. The data also revealed the linkage between the translation and some external factors, which suggested an exosystem in this study. Advertisement, existence of movie or cartoon adaptation of the book, electronic file availability, cultural similarities between source and target culture, and having common grounds with social events of Iran can be seen in this excerpt.

As can be seen in this part, there are many books that can be addressed as valuable translations and own all the criteria of a good work of art, which reflects the effect of the factors in the microsystem, yet there are sacrificed for the lack of advertisement and facilities to be introduced in the society. Or the vice versa could happen for a translation that is not outstanding at the microsystemic level but advertisement or its availability paves the way for its popularity. As for the teenagers who are the member of reading websites and read the books of anonymous authors or translators due to their download link availability. Accordingly, an acceptable and eternal translation could be the one which is admissible in all the systems.

The macrosystem, or as Vygotsky (1978) claims cultural-historical domain, was viewed to consist of overarching social and cultural factors that influence the microsystem. The data revealed that participants believed that censorship of the book affects the field of translation. Translations should pass some filters and during this process some parts of them may be removed or some books do not get the permission to be printed. The result would be translator's discouragement and limitation of the reader's choice domain.

In addition, the influence of publishing law less explicitly addressed by the interviewees was nonetheless observable. Publishing policies in Iran is usually dependent on the government, and by changing the president every four or eight years, the ministry of culture and guidance applies some changes, for example, books that were published during the presidency of someone, do not get the permission to be printed in another period; so the outcome is nothing except damage for the presses and confusion of the publisher, reader, and at the microsystemic level the translator. This also illustrates the interrelatedness of the ecosystems that jointly work on translation. 


\section{The Individual as the Core}

Since the subjects of this study are not homogenous, the analysis of their ontogenetic and cultural-historical domain should be discussed separately according to their social positions.

\section{Social Position Category}

To analyze the findings based on the participant's social positions, they were classified in 11 different groups.

\section{Booksellers}

Table 6

Major Factors of Translation Eternality Drawn from Booksellers' Interviews

\begin{tabular}{ll}
\hline Booksellers $(\mathrm{N}=11)$ & Number \\
\hline Factor & 6 \\
\hline Author's competence in writing & 5 \\
Subject of the book & 4 \\
Being both translator and author & 4 \\
Translation fluency & 4 \\
Translator's competence & 4 \\
\hline
\end{tabular}

In order to analyze booksellers' opinion about translation eternality, firstly their subsystems of ecological model are to be defined:

The microsystem of the booksellers would be their community, the customers, publishers, etc. That is, their opinion may be influenced by their colleagues, or they may become interested in an author or a translator's works when they see that their customers advocate their works. At the mesosystemic level, the booksellers' background, family, teachers, university professors (if he is graduated), and friends have impact on them. The decisions made in the field of publication, and changes in book market would be their exosystem. And the macrosystem is the same for all the people living in a society, and it consists of general policies governing the society.

As shown in the Table 2, the most frequent item proposed by the booksellers was competence; and they put the emphasis mostly on the author's competence in writing.

For the booksellers subject of the book was the second significant factor for making a translation an eternal one. Novelty in both aspects of content and form, or not being imitative in one of those was reported as the reason of translation's eternality. As one cited:

For example if the subject of the book is wife's betrayal and conviction of immorality (a subject that has been discussed over and over) it should be innovative in style, characterization and manipulation of time and space to be as unique as Othello.

Booksellers in the current study claimed that being both author and translator adds to translator's competence and consequently leads to a better translation. They said when the customers need help to choose between two translations, their suggestion is the one whose translator has the experience of authorship, too.

To them, translation fluency was one sure way to enhance the chance of a book to be accounted as an eternal one. They also believed that one could verify the competence of a translator through the fluency of his translation. 


\section{Employees}

Table 7

Major Factors of Translation Eternality Drawn from Employees’ Interviews

\begin{tabular}{ll}
\hline Employees $(\mathrm{N}=5)$ & Number \\
\hline Factor & 4 \\
\hline Author's competence in writing & 4 \\
Subject of the book & 4 \\
Translation fluency & 2 \\
Addressing common issues of human being & 2 \\
Translator's fidelity to the target language & 2 \\
Translator's competence & \\
\hline
\end{tabular}

The ecosystem of employees is their job environment, colleagues, and family at the microsystemic level; their field of study, friends, and university environment at the mesosystemic level; and the reading competition, and discount coupons for buying books at the exosystemic level. These factors influence employees' opinion at different level. For example, one of the employees said: "reading at work is not acceptable in Iran. If one sees his colleague reading book in free time, he thinks his colleague wants to escape working; and generally reading at work is not acceptable".

\section{Engineers}

Table 8

Major Factors of Translation Eternality Drawn from Engineers' Interviews

\begin{tabular}{ll}
\hline Engineers $(\mathrm{N}=4)$ & \\
\hline Factor & Number \\
\hline Addressing common issues of human being & 2 \\
Cultural similarities between source and target culture & 2 \\
To have common grounds with social events of Iran & 2 \\
\hline
\end{tabular}

Engineers' microsystem is limited to their job environment, their colleagues, and family. Their mesosystem consists of their university environment and their friends. At the exosystemic level, they may be influenced by being a member of cyberspace groups, or going to English classes.

International subject was the factor attributed to translation eternality by the engineers. They believed universal subjects are understandable, acceptable, and nevertheless favorable for the whole human beings all around the world.

The engineers also noted that as much as the distance between source culture and target culture grows, the number of cultural words (which are untranslatable in most of the cases) enhances. Therefore, it leads to the production of a vague text for the reader. So cultural similarities may pave the way for better translation.

\section{Housewives}

Table 9

Major Factors of Translation Eternality Drawn from Housewives' Interviews

\begin{tabular}{ll}
\hline Housewives $(\mathrm{N}=4)$ & \\
\hline Factor & Number \\
\hline Subject of the book & 3 \\
Author's competence in writing & 2 \\
\hline
\end{tabular}


Microsystem of the housewives is limited to their family, and their friends. Their background, and school or university environments form their mesosystem. And being a member of cyberspace groups, participating in reading communities, or watching series or movies that encourage people to read books have impact on their opinion at exosystemic level.

To the housewives, subject of the book and author's competence were the main factors leading to translation eternality. It seems that they do not focus on the details of the translation.

\section{Jobs Related to the Book}

Table 10

Major Factors of Translation Eternality Drawn from the Interviews of People Having Book Related Professions

\begin{tabular}{ll}
\hline Jobs related to the book $(\mathrm{N}=9)$ & Number \\
\hline Factor & 5 \\
\hline Translation fluency & 3 \\
Subject of the book & 3 \\
\hline To have common grounds with social events of Iran & \\
\hline
\end{tabular}

This group consists of an author, a book critic, a chief editor of a magazine, a director of public relations of cultural center, an interpreter, two librarians, and two translators, and consequently their ecosystem is different from one another.

To them, translation fluency seems to be the most important one. Subject of the book and having common grounds with social events of Iran were at the second and third place respectively. The book critic asserted:

Those books which are published in a certain period, and are about the current events of the country always have a welcoming audience. They remain in people's mind, and when talking about that event they associated with they will be remembered, too.

\section{Publishers}

Table 11

Major Factors of Translation Eternality Drawn from Publishers' Interviews

\begin{tabular}{ll}
\hline Publishers $(\mathrm{N}=6)$ & Number \\
\hline Factor & 4 \\
\hline Author's competence & 4 \\
Subject of the book & 3 \\
Translation fluency & 2 \\
Translator's competence & 2 \\
\hline
\end{tabular}

The publishers' microsystem consists of their colleagues and their family. At their mesosystem their family and their background exists. And at the exosystem the policies of publication industry and changes in book market affect their opinion of translation eternality.

Publishers in this study were inclined to highlight author's competence role in eternality of the book. Considering competence of author as the key of success, publishers claimed they are mostly willing to publish those books written by famous authors rather than by anonymous ones.

Publishers believed that in the current society of Iran, due to the economic problems, people's interests for reading have changed. They asserted that today books about positive thinking and strategies to earn great 
wealth are the best selling books. They also put the emphasis on the fluency of the text.

\section{Researchers}

Table 12

Major Factors of Translation Eternality Drawn from Researchers' Interviews

\begin{tabular}{ll}
\hline Researchers $(\mathrm{N}=5)$ & Number \\
\hline Factor & 4 \\
\hline Others' suggestion & 4 \\
Subject of the book & 3 \\
Translation fluency & 2 \\
\hline
\end{tabular}

The researcher's have their colleagues and their family at their microsystem; their childhood, friends, and university environment are at their mesosystem. Being a member of cyberspace groups, or some interesting incidents that may influence their opinions about reading while doing researches are at their exosystemic level.

Researchers believed that books that were suggested to them by their friends, family, teachers, or university professors are of those which are worth reading and can be labeled as eternal ones.

Apart from that, subject was a main factor, too. Fluency of the translation was also mentioned by them frequently. Translator's fidelity was what the researcher took into consideration when choosing a book, either.

\section{Students}

Table 13

Major Factors of Translation Eternality Drawn from Students' Interviews

\begin{tabular}{ll}
\hline Students $(\mathrm{N}=6)$ & Number \\
\hline Factor & 5 \\
\hline Others' suggestion & 4 \\
Electronic file availability & 4 \\
Existence of movie or cartoon adaptation of the book & 3 \\
Advertisement & 3 \\
Name of the book & 2 \\
Author's popularity & 2 \\
Cover of the book & 2 \\
\hline
\end{tabular}

Friends and family are the microsystem of students. Their school environment, teachers, and classmates are at their mesosystemic level, and cyberspace groups' membership, reading cites, café books, and movies or TV series which encourage them to read books at the exosystemic level.

For them, others' suggestion (mostly their friends or teacher's) is the most encouraging factor to choose a book. Electronic file availability was the next. They claimed that they are willing to read books in their smart phones; hence they do not advocate paper version. Majority of the students said that they are member of reading websites and they usually download their favorite books. Aside from interest, the other reason is that students do not like to spend money on buying books.

Movie or cartoon adaptation of the books can lead the students to read the books associated with them. Advertisement was the next factor mentioned by them, but the interesting point to mention was that they did not mean advertisement in media, TV, radio, or newspapers. They read the comments of other members of the 
reading website and choose the books based on their view. For example, if a book was acclaimed by many members, they would be encouraged to download and read that.

To the students name of the book is encouraging. They said a picturesque or strange name can attract them to that book. According to the student's talks popularity of the author is important for them. If choices were presented to them, they would rather opt for the books with known authors rather those that they did not heard of their names and works.

Cover of the book is another factor mentioned by the students. The appearance of the book can absorb them for instance packet size books or those with fantasy covers are more preferable to them.

\section{Teachers}

Table 14

Major Factors of Translation Eternality Drawn from Teachers' Interviews

\begin{tabular}{ll}
\hline Teachers $(\mathrm{N}=8)$ & Number \\
\hline Factor & 5 \\
\hline Subject of the book & 3 \\
To have common grounds with social events of Iran & 3 \\
Translator's awareness of the content of the book & 3 \\
\hline Translator's competence & \\
\hline
\end{tabular}

Schools, students, and colleagues are placed at the microsystemic level of the teachers. To them, family, field of study, and university environment are at the mesosystem. And membership of cyberspace groups, libraries, or literary communities are limited to their exosystemic level.

Like many others teachers also believed that subject of the book is the most significant factor in eternality of a translation. Secondly, being related to trends and events of the society was mentioned by them.

\section{University Professors}

Table 15

Major Factors of Translation Eternality Drawn from University Professors' Interviews

\begin{tabular}{ll}
\hline University professors $(\mathrm{N}=5)$ & Number \\
\hline Factor & 2 \\
\hline Subject of the book & 2 \\
Translation fluency & 2 \\
\hline
\end{tabular}

University environment, students, and colleagues belong to the microsystem of university professors. They may be influenced by their background and their university environment from which they were graduated at the mesosystemic level. And their exosystem is limited to membership of cyberspace groups and participating in conferences. University professors in this study mostly criticized translations and translators. Among their talks the items that were repeated were subject of the book and translation fluency. 


\section{University Students}

Table 16

Major Factors of Translation Eternality Drawn from University Students' Interviews

\begin{tabular}{ll}
\hline University Students $(\mathrm{N}=11)$ & Number \\
\hline Factor & 7 \\
\hline Subject of the book & 5 \\
Others' suggestion & 5 \\
Translator's competence & 4 \\
Translation fluency & 4 \\
To have common grounds with social events of Iran & 3 \\
Author's competence in writing & 3 \\
To use conversational language & \\
\hline
\end{tabular}

University students' opinion may be under the influence of their classmates, friends, professors, and family at the microsystemic level. Their mesosystem consists of their school environment and their teachers. And their exosystemic level consists of being member of cyberspace groups, café books, and getting discount coupon from university.

To the university students like other groups of people subject, competence of the producers, fluency of the text, and being related to social events were the main factors suggested for the translation eternality. The different idea of them was using conversational language in translation. This indicates that new generations are not willing to use sophisticated or complex languages.

\section{Conclusion}

In short, people's conception of eternal translation and the factors influencing their opinion have not been widely studied. This study attempted to fill this gap through the use of qualitative data collection and analysis. The study showed that subject of the book was the most frequent factor in people's view. The other factors of eternality of translated literature are translation fluency, author's competence in writing, translator's competence, having common grounds with social events of Iran, others' suggestions of the books, advertisement, existence of movie or cartoon adaptation of the book, translator's awareness of the content of the book, existence of cultural similarities between source and target culture, popularity of the translator, author, and book, to have conversational language, and being both translator and author. They also believed not being censored and taking advantage of advertisement may help a book to be eternal, but the authorities do not take this issue into consideration. According to Vygotsky's (1987) development theory, such contrasts are due to discrepancies between individual's ontogenetic and socio historical development. Similarly, for censorship it can be concluded that the individual's macrosystem does not match with his meso- or microsystem.

Besides, participants had paradoxical view on translator's fidelity to the source text. They said an eternal translation should be faithful to the original text, on the contrary, they named translations (or more precisely, adaptation) of Zabihollah Mansoori as eternal ones. Old participants seemed to have a more precise view on translation eternality. It seemed that the main concern of teenagers was some appearance-related issues of the book. Moreover, interviewees believed that advertisement can be an affecting factor; however, authorities do not take advantage of that in Iran. The data depicts that teenagers were mostly concerned with the appearance of the book, and its availability in the Internet, which can be originated in their ontogenetic development of them. 
The participant's of different social positions did not have similar view to translation eternality. This diversity in opinion seemed to be originated in their various ecosystems.

The participants of different ages also had not similar opinion about eternality of the translated literature. Their disagreement is rooted in their different ontogenetic development and also their different ecosystems.

\section{References}

Bassnett, S., \& Lefevere, A. (1998). Constructing cultures: Essays on literary translation (Vol. 11). Clevedon: Multilingual Matters.

Bronfenbrenner, U. (1979). Contexts of child rearing: Problems and prospects. American Psychologist, 34(10), 844.

Bronfenbrenner, U. (1993). The ecology of cognitive development. In R. Wozniak and K. Fischer (Eds.), Scientific environments (pp. 3-44). Hills-dale, NJ: Erlbaum.

Buzelin, H. (2007). Translations “in the making”. Benjamins Translation Library, 74, 135.

Chesterman, A. (2007). Bridge concepts in translation sociology. Benjamins Translation Library, 74, 171.

Dörnyei, Z. (2007). Research methods in applied linguistics: Quantitative, qualitative, and mixed methodologies. Oxford: Oxford University Press.

Erikson, E. H. (1959). Identity and the life cycle: Selected papers. Psychological Issues, 1(1).

Even-Zohar, I. (1978). Papers in historical poetics (Vol. 15). Tel Aviv: Porter Institute for Poetics and Semiotics.

Even-Zohar, I. (1990). Laws of literary interference. Poetics Today, 11(1), 53-72.

Farquhar, S., \& Fitzsimons, P. (2011). Lost in translation: The power of language. Educational Philosophy and Theory, 43(6), 652-662.

Goffman, E. (1981). Forms of talk. Pennsylvania: University of Pennsylvania Press.

Khazaeefar, A. (1993). Goftogoo ba Mohammad Ghazi (Interview with Mohammad Ghazi). Faslname Motarjem, 3(9).

Khazaeefar, A. (2015). Goftogoo ba Abdolhossein Azerang (Interview with Abdolhossein Azerang). Retrieved from $\mathrm{http} / / /$ motarjemjournal.ir/wp-content/uploads/2015/03/.pdf

Lefevere, A. (1992). Translation, rewriting, and the manipulation of literary fame. London: Taylor \& Francis.

Munday, J. (2009). Introducing translation studies: Theories and applications. London: Routledge.

Newmark, P. (1988). A textbook of translation (Vol. 1, p. 988). New York: Prentice Hall.

Orozco, M., \& Hurtado Albir, A. (2002). Measuring translation competence acquisition. Meta: Translators' Journal, 47(3), 375-402.

Perteghella, M., \& Loffredo, E. (2006). Translation and creativity: Perspectives on creative writing and translation studies. New York: Continuum.

Rahim Pour, R. (2002). Goftogoo ba Soroush Habibi (Interview with Soroush Habibi). Faslname Motarjem, 36(11).

Solhjoo, A. (2006). Goftogoo ba Leili Golestan (Interview with Leila Golestan). Faslname Motarjem, 16(44), 36-44.

Susan, B., \& Lefevere, A. (1990). Translation, history and culture. London and New York: Pinter.

Tudge, J. (1997). Internalization, externalization, and joint-carving: Commenting from an ecological perspective. In B. Cox and C Lightfoot (Eds.), Sociogenetic perspectives on internalization (pp. 119-131). Mahwah, NJ: Erlbaum.

Tudge, J., \& Hogan, D. (2005). An ecological approach to observations of children's everyday lives. In Researching children's Experience: Approaches and methods (pp. 102-122). London, Thousand Oaks and New Delhi: Sage.

Venuti, L. (1996). Translation as social practice: Or, the violence of translation. In M. G. Rose (Ed.), Translation horizons beyond the boundaries of translation spectrum (Translation perspectives IX) (pp. 195-214). Binghamton: State University of New York at Binghamton.

Venuti, L. (2008). The translator's invisibility: A history of translation. New York: Routledge.

Vygotsky, L. S., \& Luria, A. (1994). Tool and symbol in child development. In R. Van Der Veer and J. Valsiner (Eds.), The Vygotsky reader (pp. 99-174). Cambridge: Blackwell.

Wolf, M., \& Fukari, A. (Eds.). (2007). Constructing a sociology of translation (Vol. 74). Amsterdam \& Philadelphia: John Benjamins Publishing. 